\title{
Inhibitory short peptides targeting EPS8/ ABI1/SOS1 tri-complex suppress invasion and metastasis of ovarian cancer cells
}

\author{
Xuechen $\mathrm{Yu}^{1 \dagger}$, Chuan Liang ${ }^{2 \dagger}$, Yuanzhen Zhang ${ }^{1}$, Wei Zhang ${ }^{1}$ and Huijun Chen ${ }^{1 *}$ (D)
}

\begin{abstract}
Background: We aimed to develop inhibitory short peptides that can prevent protein interactions of SOS1/EPS8/ ABl1 tri-complex, a key component essential for ovarian cancer metastasis.

Methods: Plasmids containing various regions of HA-tagged ABI1 were co-transfected into ovarian cancer cells with Flag-tagged SOS1 or Myc-tagged EPS8. Co-immunoprecipitation and GST-pulldown assay were used to identify the regions of ABI1 responsible for SOS1 and EPS8 binding. Inhibitory short peptides of these binding regions were synthesized and modified with HIV-TAT sequence. The blocking effects of the peptides on ABI1-SOS1 or ABI1-EPS8 interactions in vitro and in vivo were determined by GST-pulldown assay. The capability of these short peptides in inhibiting invasion and metastasis of ovarian cancer cell was tested by Matrigel invasion assay and peritoneal metastatic colonization assay.
\end{abstract}

Results: The formation of endogenous SOS1/EPS8/ABI1 tri-complex was detected in the event of LPA-induced ovarian cancer cell invasion. In the tri-complex, ABl1 acted as a scaffold protein holding together SOS1 and EPS8. The SH3 and poly-proline+PxxDY regions of ABI1 were responsible for SOS1 and EPS8 binding, respectively. Inhibitory short peptides p + p-8 (ppppppppvdyedee) and SH3-3 (ekvvaiydytkdkddelsfmegaii) could block ABI1SOS1 and ABI1-EPS8 interaction in vitro. TAT- $p+p-8$ peptide could disrupt ABI1-EPS8 interaction and suppress the invasion and metastasis of ovarian cancer cells in vivo.

Conclusions: TAT- $p+p-8$ peptide could efficiently disrupt the ABI1-EPS8 interaction, tri-complex formation, and block the invasion and metastasis of ovarian cancer cells.

Keywords: Ovarian cancer metastasis, Inhibitory short peptide, ABI1, SOS1, EPS8

\section{Background}

Ovarian cancer has the highest mortality rate among all the gynecological cancers [1]. Due to the lack of symptoms at early stages and effective screening strategies, $75 \%$ of patients with ovarian cancer usually have extensive metastasis at diagnosis [2]. In the past decades, advances in surgical techniques and chemotherapy have not effectively improved the survival of ovarian cancer patients [3]. Therefore, novel therapeutic strategies targeting the metastatic process of ovarian cancer are urgently needed.

\footnotetext{
* Correspondence: karrel@sina.com

${ }^{+}$Xuechen Yu and Chuan Liang contributed equally to this work.

${ }^{1}$ Department of Gynaecology and Obstetrics, Zhongnan Hospital of Wuhan University, Wuhan 430071, Hubei, China

Full list of author information is available at the end of the article
}

Ovarian cancer mostly originates from malignant transformation of epithelial cells on the ovary surface. Unlike other solid tumors that rely on the vasculature for metastasis, ovarian cancer mainly disseminates throughout the peritoneal cavity with the flow of ascites, and implants onto the peritoneal organs [4-6]. Lysophosphatic acid (LPA) is a growth factor-like phospholipid, which can be produced and secreted into peritoneal cavity by ovarian cancer cells [6-9]. High concentrations of LPA have been found within the ascites of ovarian cancer patients [10].

LPA and its receptors have been recognized to play a critical role in the metastasis of ovarian cancer $[11,12]$. Our previous study demonstrated that LPA could stimulate Rac activation, cytoskeleton reorganization, and ovarian

(c) The Author(s). 2019 Open Access This article is distributed under the terms of the Creative Commons Attribution 4.0 International License (http://creativecommons.org/licenses/by/4.0/), which permits unrestricted use, distribution, and 
cancer cell migration through a signaling pathway consisting of Ras-SOS1/EPS8/ABI1 tri-complex [14]. The integrity of SOS1/EPS8/ABI1 tri-complex may determine ovarian cancer metastatic potentials, as silencing any member of SOS1/EPS8/ABI1 tri-complex is sufficient to diminish the migration and metastatic colonization of ovarian cancer cells [14]. These results implicate SOS1/EPS8/ABI1 tricomplex as an ideal therapeutic target, and disrupting the tri-complex may suppress the metastatic process of ovarian cancer. Among the tri-complex, SOS1 functions as a Racspecific guanine nucleotide exchange factor (GEF), which finally induces Rac-regulated cytoskeleton recombination and cell migration [15-17]. EPS8 acts as a substrate for the tyrosine kinase receptors. ABI1 is a scaffold protein that connects SOS1 and EPS8 [18-24]. ABI1 binds to SOS1 with its $\mathrm{SH} 3$ domain [25], and then to the $\mathrm{SH} 3$ domain of EPS8 [26]. In this study, we found that the SH3 and polyproline+PxxDY regions of $\mathrm{ABI} 1$ are responsible for its interaction with SOS1 and EPS8, respectively.

The development of biology is helpful in finding therapeutic targets for diseases [27]. Biomedicine has made great progress in cancer treatment [28]. Recent studies have shown the success of using inhibitory peptides to disrupt specific protein-protein interactions and their pertinent biological events [29-32]. As small molecules, inhibitory peptides also hold tremendous promise for clinical applications. Peptides have made great progress in the fields of vaccines, antibiotics, antitumor drugs, and diagnostic agents [33]. Recently, short peptides have been successfully used in interfering with signaling pathways as new therapeutic tools for cancer treatment [34, 35].

In this study, we developed peptides that can inhibit the EPS8-ABI1 and ABI1-SOS1 interactions and tested their efficacies in suppressing ovarian cancer metastasis. Because of the nature of ABI1 as an adaptor protein $[18,22]$ and the smallest size among the three members of tri-complex, we chose ABI1 as a target for designing short inhibitory peptides. We identified the respective amino acid regions in ABI1 essential for SOS1 or EPS8 bindings, generated overlapping peptides covering these regions, and identified the peptides that could prevent the formation of SOS1/EPS8/ ABI1 tri-complex. We believe that the inhibitory peptides developed in this study can represent a new line of therapeutic agents against ovarian cancer metastasis.

\section{Methods}

\section{Cells and antibodies}

The human ovarian cancer cell lines SK-OV3, HEY, and OVCAR3 were gifted to us by the Department of Biochemistry and Molecular Biology, Georgia Regents University (Georgia, USA). Cells were cultured in Dulbecco's modified Eagle's medium (DMEM) supplemented with $10 \%(\mathrm{w} / \mathrm{v})$ fetal bovine serum (FBS) at $37^{\circ} \mathrm{C}$ in a humidified incubator containing $5 \% \mathrm{CO}_{2}$. LPA was purchased from Avanti Lipid (Alabaster, AL). DMEM, serum, and other cell culture supplies were from Hyclone (Waltham, MA). SOS1 mAb was purchased from Santa Cruz Biotechnology Inc. (Cat\#: sc-55,528, titer: 1:2000), EPS8 mAb from BD Biosciences (Cat\#: 610144, titer: 1:1000), and ABI1 mAb from MBL international Corporation (Cat\#: D147-3, titer: 1:1000).

\section{Construction and infection of plasmids}

Vectors containing the coding sequences of human EPS8, SOS1, and ABI1 were purchased from Openbiosystems (Lafayette, CO). Lentiviral vectors encoding EPS8, SOS1, and ABI1 were prepared by subcloning these coding sequence into $\mathrm{PCDH}-\mathrm{CMV}-\mathrm{MCSEF} 1-\mathrm{Puro}$ vector, and tagged with Myc, Flag, and HA, respectively. OVCAR3 cells were transfected with two of the three expression plasmids (Myc-EPS8, HA-ABI1, and FlagSOS1) and chosen by puromycin. The efficiency of MycEPS8, HA-ABI1 and Flag-SOS1 overexpression was analyzed by western blotting. After $12 \mathrm{~h}$ starvation, cells were stimulated with $20 \mu \mathrm{M}$ LPA and followed by Co-IP assay. To determine the regions of ABI1 responsible for EPS8 and SOS1 binding, we divided ABI1 into the following regions: WAB (aa: 1-79), SNARE (aa: 45-107), HHR (aa: 93-169), proline-rich (aa: 170-340), poly-proline (aa: 341-418), and SH3 (aa: 419-508) (Fig. 2a). We generated plasmids containing HA-tagged regions of ABI1 described above, using the pCDH-CMV-MCSEF1Puro vector. OVCAR3 cells were co-transfected with these plasmids along with Flag-tagged SOS1 or Myctagged EPS8. Recombinant plasmids with Flag-tagged proline-rich region of SOS1 (aa: 1131-1333) and Myctagged SH3 region of EPS8 (aa: 535-586) were also prepared using the same procedure.

\section{Matrigel invasion assay}

The Matrigel invasion assay was performed as per manufacturer's instructions (Corning Incorporated, MA, USA). Briefly, LPA was dissolved in serum-free medium $(20 \mu \mathrm{M})$ and added into the lower chambers of the invasion plates to induce cell invasion. Serum-free medium without LPA was used as control. Serum-starved ovarian cancer cells $\left(10^{5} /\right.$ well, in log phase) were added into the chambers and allowed to invade for $48 \mathrm{~h}$. The cells that remained in the chambers were removed and the invaded cells on the lower surface of the chambers were fixed and stained with crystal violet. The crystal violetstained cells were solubilized with $10 \%$ acetic acid and quantified on a microplate reader at $600 \mathrm{~nm}$. Fold increase in cell invasion was calculated to evaluate cells' responsiveness to LPA $\left(\mathrm{OD}_{600} \mathrm{LPA}\right.$-induced cell invasion/OD 600 base cell invasion) [36]. 


\section{Co-immunoprecipitation (co-IP)}

The cells were detached and resuspended in $1 \mathrm{ml}$ lysis buffer. The cell lysates were centrifuged for $5 \mathrm{~min}(8000 \mathrm{rpm}$ $4{ }^{\circ} \mathrm{C}$ ). The supernatant was transferred into another tube and incubated with the anti-ABI1 antibody $(2 \mu \mathrm{g})$ at $4{ }^{\circ} \mathrm{C}$ overnight. Then, $\gamma$-bound beads $(50 \mu \mathrm{l})$ were added, and the mixture was incubated for another hour. The mixture was centrifuged for $5 \mathrm{~min}\left(8000 \mathrm{rpm} 4{ }^{\circ} \mathrm{C}\right)$, the supernatant was carefully removed, and the beads were washed four times for $10 \mathrm{~min}$. The interactions between ABI1 and the EPS8 or SOS1 were detected by western blotting using anti-EPS8 or anti-SOS1 antibody. The same procedure was adopted in all the other Co-IP experiments. Image 1.41 software (National Institute of Health, Bethesda, MD, USA) was used to quantified the intensity of the western blotting bands. The expression of same protein in the cell lysis was used as an internal control. The band intensity of each sample were normalized by the cell lysis that detected the same protein, and then compared with control. Three repeats were set up for each experiment.

\section{GST (glutathione-S-transferase)-fusion protein pull-down assay}

The BL21 competent cells were transfected with the vector expressing each domain of ABI1, incubated until they reached an $\mathrm{OD}_{600}$ of $0.4-0.5$, and then induced by IPTG. Expressed proteins were extracted from BL21 cells and incubated with the GST Beads overnight for GST fusion proteins. The expression and purification effects were analyzed by SDS-PAGE. The lysates from ovarian cancer cells were incubated with ABI1-GST Beads for $4 \mathrm{~h}$ and the EPS8 or SOS1 expression was analyzed by western blotting using anti-EPS8 or anti-SOS1 antibodies. ImageJ 1.41 software was used to quantified the intensity of the western blotting bands. The same procedure was adopted in all the other GST-fusion protein pull-down assays.

\section{Peritoneal metastatic colonization assay}

Ovarian cancer cells in log-phase were trypsinized, washed twice with PBS, and resuspended. Six-week-old athymic female homozygous nu/nu mice (Beijing Hua Fukang biological Polytron Technologies Inc.) were intraperitoneally injected with ovarian cancer cells $\left(10^{7}\right.$ cells $/ 0.2 \mathrm{ml} \mathrm{PBS} /$ mice). Seventy-two hours after injection, mice were divided into several groups (six mice/ group) and PBS, TAT-fused scramble peptides or TATfused inhibitory short peptides (TAT-p $+\mathrm{p}-8$, TAT$\mathrm{SH}-3)$ were administered by intraperitoneal injections, at a dose of $0.5,3$ and $15 \mathrm{nmol} / \mathrm{g}$ body weight. Then, the peptides were given to the animals every 2 days for a total of 4 weeks. After which, the mice were sacrificed by cervical dislocation, autopsied. Metastatic implants were collected and weighed [37]. All animal experiment procedures were approved by the Animal Center of Wuhan University. All the procedures were performed in accordance with the relevant guidelines and regulations.

\section{Statistical analysis}

SPSS24.0 was used for all statistical analyses. Statistical analyses were performed with ANOVA and independent $t$-test. Chi-square test and Fisher's exact test were used to analyze the data. All the statistical tests were twosided and a $P$-value of less than 0.05 was considered statistically significant.

\section{Results}

The formation of endogenous SOS1/EPS8/ABI1 tricomplex in ovarian cancer cell invasion

In vitro formation of SOS1/EPS8/ABI1 tri-complex with GST recombinant proteins have been previously reported [18, 20, 22]. We thus employed the Co-IP assay as a confirmative approach. We first treated metastatic ovarian cancer cell line SK-OV3 with LPA for $5 \mathrm{~min}$ to induce cell invasion. Cells were then lysed and incubated with anti-ABI1 antibody as well as $\gamma$-bound beads. Subsequently, the expression of SOS1 or EPS8 was detected by immunoblotting with respective antibodies. It was found that, in the anti-ABI1 immunoprecipitates, the other two proteins could be detected (Fig. 1a). These results demonstrated the formation of endogenous SOS1/ EPS8/ABI1 tri-complex in the event of LPA-induced ovarian cancer cell invasion.

\section{ABI1 serves as a scaffold protein in SOS1/EPS8/ABI1 tri- complex}

To determine whether ABI1 mediates the interaction between EPS8 and SOS1, as expected in the tri-complex model, the experiments have to be performed under conditions in which the endogenous formation of SOS1/ EPS8/ABI1 tri-complex is disrupted. Thus, we performed Co-IP in OVCAR3 cell line, which demonstrated a lack of ABI1 expression in our previous study. We constructed Myc-tagged EPS8, HA-tagged ABI1, and Flag-tagged SOS1 recombinant plasmids (Fig. 1b). OVCAR3 cells were transfected with two of the three expression plasmids (Myc-EPS8, HA-ABI1, and FlagSOS1). Cell lysates were collected after LPA stimulation. The results of Co-IP showed that there were interactions between ABI1-SOS1 and ABI1-EPS8, but SOS1 and EPS8 could not bind directly with each other (Fig. 1c). These results indicated the role of ABI1 as a scaffold protein in connecting SOS1 and EPS8.

\section{Characterizing the regions of $\mathrm{ABI} 1$ that mediate its interaction with SOS1 and EPS8}

Because ABI1 functions as a scaffold protein and has the smallest size in the tri-complex (508 aa vs. 1333 aa for 


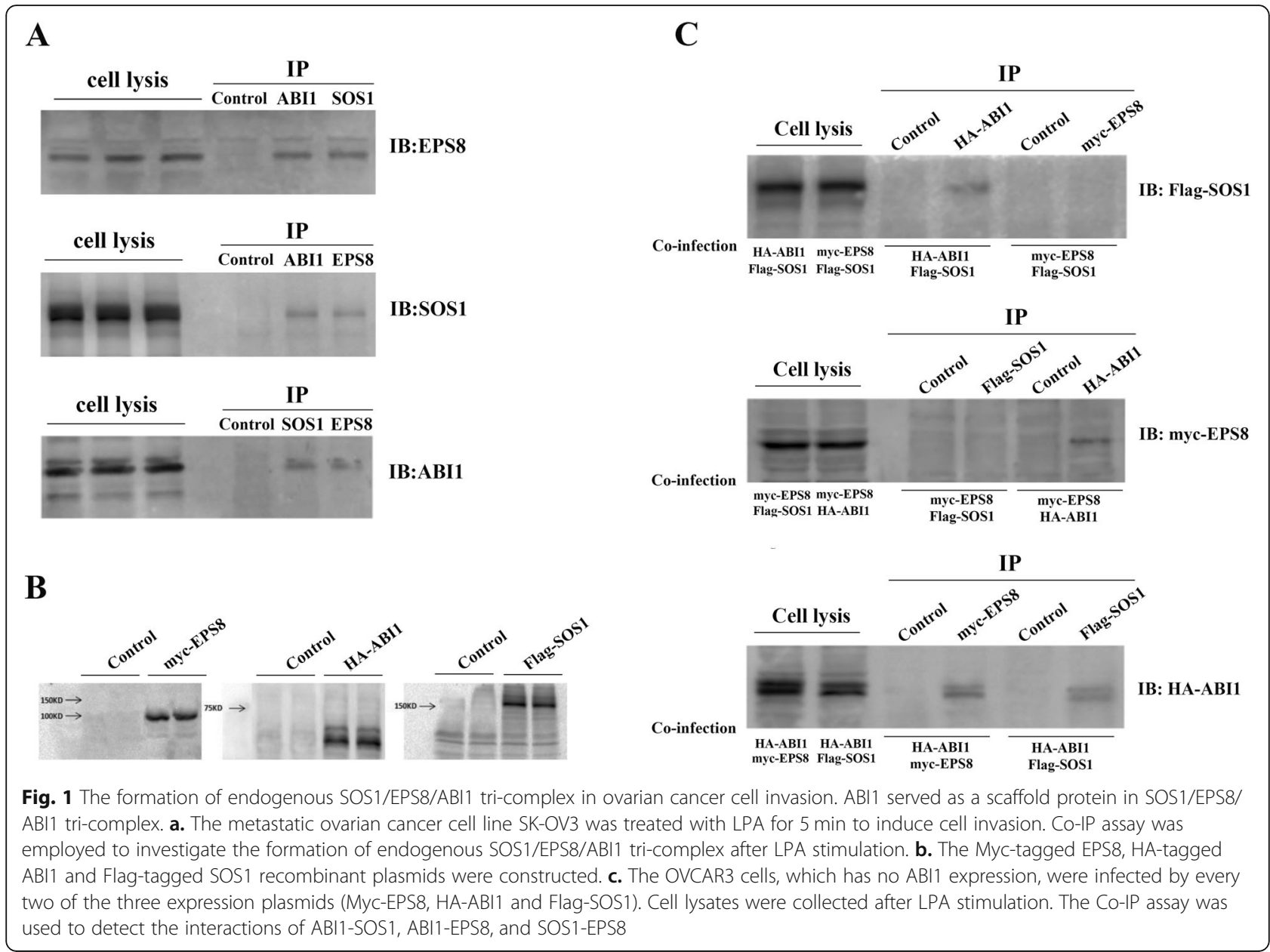

SOS1 and 822 aa for EPS8), we focus on finding the regions of ABI1 that mediate SOS1 and EPS8 binding. Based on web-based protein domain searching programs and published literatures [38-45], we identified multiple motifs that could potentially mediate protein-protein interactions, and divided ABI1 into the following regions: WAB (aa: 1-79), SNARE (aa: 45-107), HHR (aa: 93-169), proline-rich (aa: 170340), poly-proline (aa: 341-418), and SH3 (aa: 419508) (Fig. 2a). Then we generated plasmids containing HA-tagged regions of ABI1 described above, using the pCDH-CMV-MCSEF1-Puro vector. (Fig. $2 \mathrm{~b})$. The empty vector was used as control. These plasmids were co-transfected into OVCAR3 cells along with Flag-tagged SOS1 or Myc-tagged EPS8. Cell lysates were collected after LPA stimulation. Co-IP was performed to map out the regions in ABI1 responsible for ABI1-SOS1 and ABI1-EPS8 interactions. The results showed that Flag-SOS1 could only be detected in the Co-IP products of anti-HA$\mathrm{SH} 3$ antibody, which indicated that the $\mathrm{SH} 3$ region of ABI1 mediated the ABI1-SOS1 interaction (Fig. 2c). On the contrary, no expression of Myc-EPS8 was found in the Co-IP products of any ABI1 regions (Fig. 2c). Since the non-traditional proline rich domain, namely PxxDY motif, was reported to interact with SH3 domain, we re-divided the C-terminal of $\mathrm{ABI} 1$ into the following regions: poly-proline+SH3 (aa: 341-508), poly-proline+PxxDY (aa: 341-425), poly-proline (aa: 341-418), and PxxDY (aa: 414425). HA-tagged plasmids containing those regions were generated. Co-IP was performed to further determine which region mediated the ABI1-EPS8 interaction. It was found that poly-proline+PxxDY region of ABI1 was responsible for its interaction with EPS8 (Fig. 2d).

To verify the above results, we employed the GSTpulldown assay as a validation method. We first prepared recombinant GST-fused beads with various ABI1 fragments. These beads were incubated with LPAtreated OVCAR3 cell lysates for $2 \mathrm{~h}$, and subsequently analyzed by immunoblotting to detect SOS1 or EPS8 expression. Results from these experiments also identified the $\mathrm{SH} 3$ and poly-proline+PxxDY as the regions in ABI1 


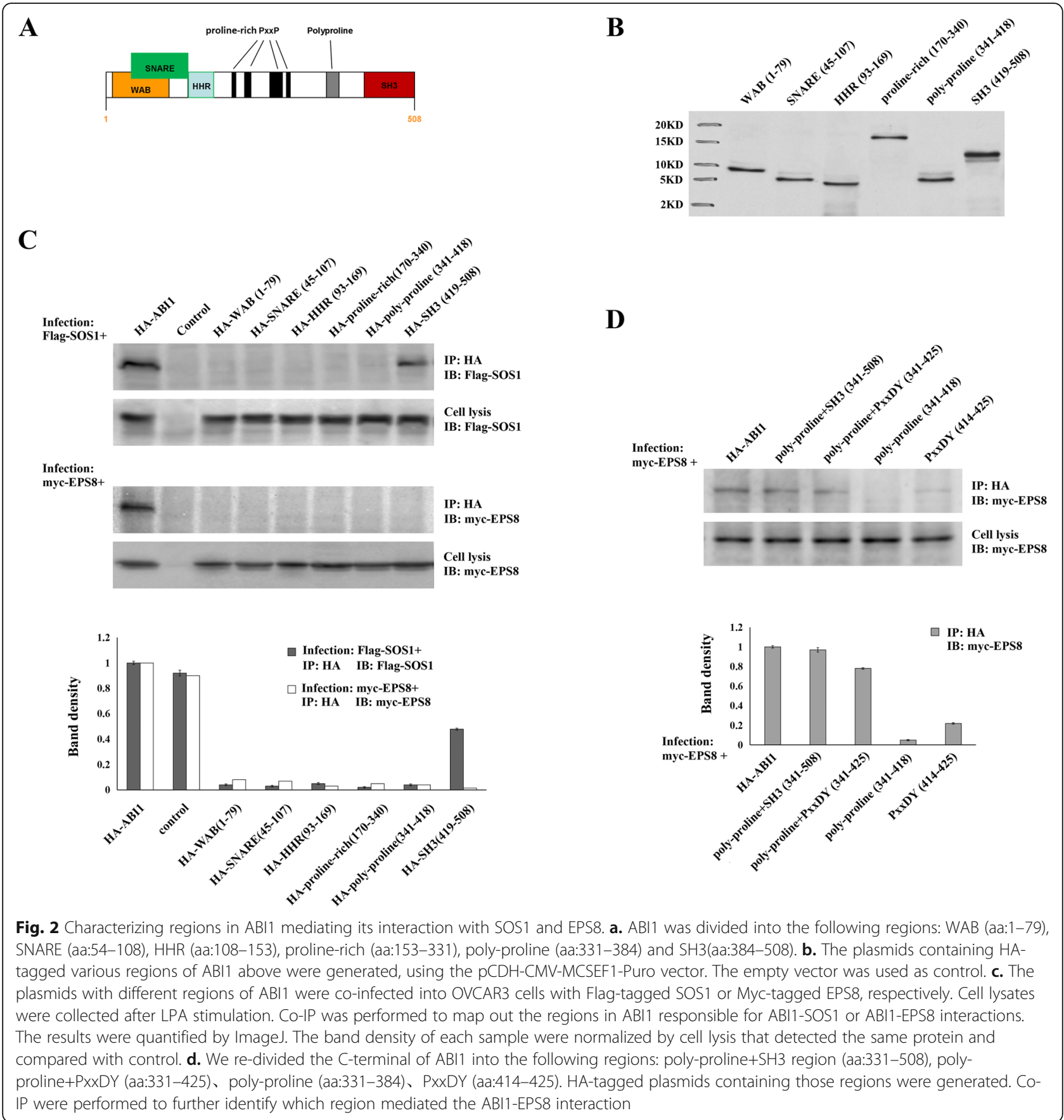

responsible for SOS1 and EPS8 interaction, respectively (Fig. 3a).

\section{Characterizing the regions which mediate the interaction of SOS1 and EPS8 with ABI1}

Previous studies have shown that ABI1 binds to the proline-rich domain of SOS1 through its SH3 domain, and the SH3 domain of EPS8 through its poly-proline+PxxDY region [20-22, 43]. To confirm this, we constructed recombinant plasmids with Flag-tagged proline-rich region of SOS1 (aa: 1131-1333) and Myctagged SH3 region of EPS8 (aa: 535-586). These plasmids were then co-transfected with HA-tagged ABI1 into OVCAR3 cells. Cell lysates were collected after LPA stimulation. The results from Co-IP demonstrated that the proline-rich region of SOS1 mediated its interaction with $\mathrm{ABI} 1$, while EPS8 bond to $\mathrm{ABI} 1$ by its $\mathrm{SH} 3$ region (Fig. 3-B). 


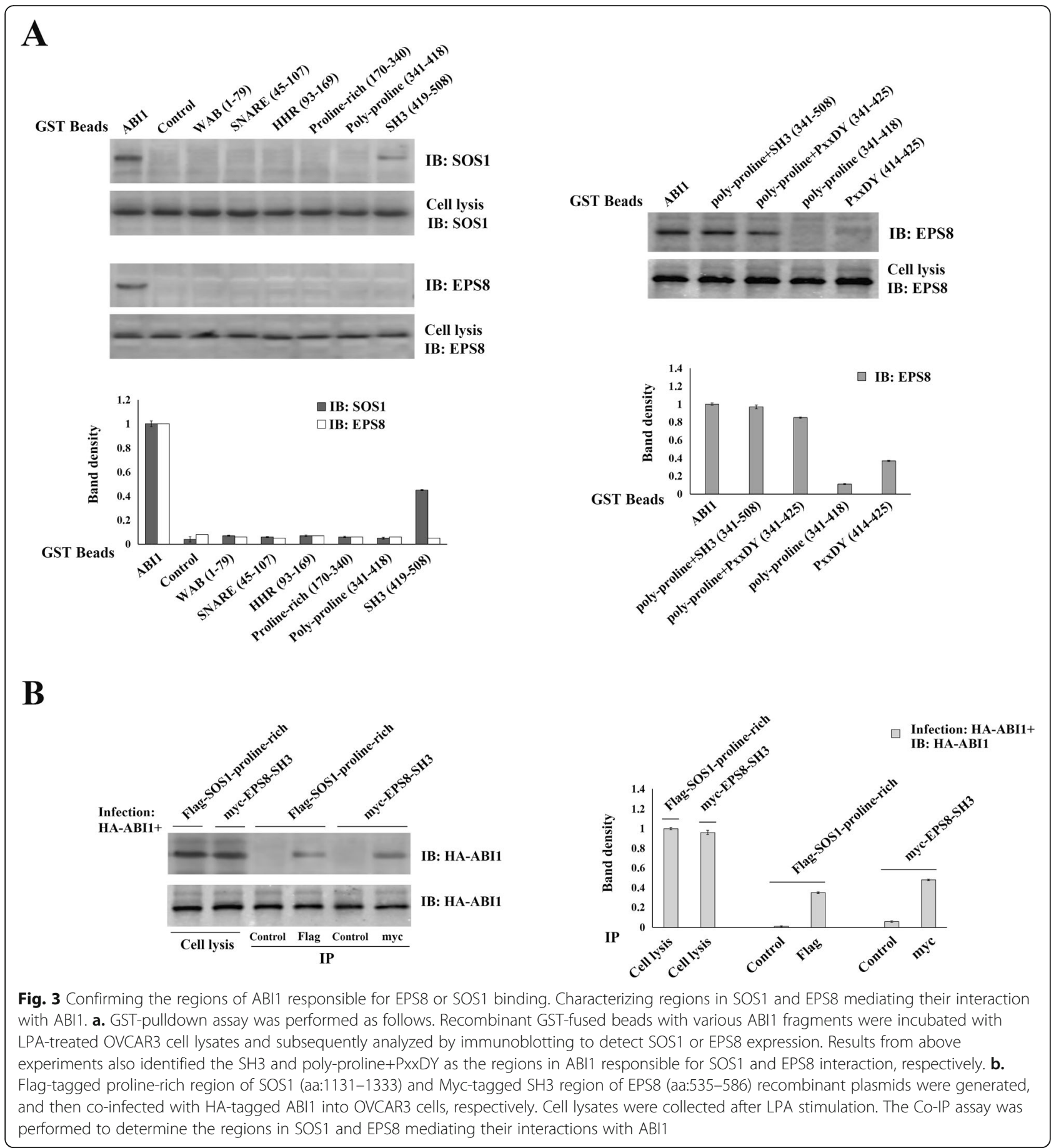

\section{Developing inhibitory short peptides that can disrupt SOS1/EPS8/ABI1 tri-complex}

Inhibitory peptides have shown great success in preventing protein-protein interactions. These peptides are generated based on the amino acid sequences essential for the respective protein interactions, and therefore have high specificity [31].

In the experiments described above, we determined the regions in ABI1 responsible for binding SOS1 or
EPS8. We then generated a series of synthetic inhibitory short peptides (each with 15 aa and overlapped by 5 aa) according to the sequence of poly-proline+PxxDY and $\mathrm{SH} 3$ regions of ABI1, through a commercial source. Efficient inhibitory short peptides are supposed to competitively inhibit the protein-protein interactions, and eventually block the formation of SOS1/EPS8/ABI1 tricomplex. GST-pulldown was employed to determine the inhibitory activity of these peptides on ABI1-SOS1 or 
ABI1-EPS8 interactions. Briefly, after LPA stimulation, inhibitory short peptides $(10 \mu \mathrm{M})$ were added into SKOV3 cell lysates $1 \mathrm{~h}$ prior to incubation with GST-ABI1 beads. Then the beads were washed and analyzed by immunoblotting to detect SOS1 or EPS8 expression. Unrelated scrambled peptides were used as control. Results from these experiments identified $\mathrm{p}+\mathrm{p}-8$ (ppppppppvdyedee) as the short peptide capable of blocking in vitro ABI1-EPS8 interaction (Fig. 4-a). However, none of these peptides could inhibit the interaction between ABI1 and SOS1 (data not shown).

Considering the possible effects that tertiary structure might have on protein interactions, we thought that the 15 aa long peptides may lack the tertiary structure necessary for binding. Thus, we redesigned the peptides with longer sequences. Six inhibitory short peptides were synthesized according to the SH3 (aa: 419-508) region of ABI1 (each had a length of 25 aa and overlapped by $10 \mathrm{aa})$. The result of GST-fusion protein pull-down assay demonstrated that SH3-3 (ekvvaiydytkdkddelsfmegaii) was the short peptide that could effectively inhibit the combination of ABI1 and SOS1. (Fig. 4b).

\section{Confirming the SOS1/EPS8/ABI1 tri-complex disrupting capability of the inhibitory short peptides in vivo}

After identifying the most efficient inhibitory peptides, we further investigated their capability of preventing formation of SOS1/EPS8/ABI1 tri-complex in vivo. HIVTAT sequence (YGKKRRQRRPP) is a very effective cell membrane-penetrating peptide, which has been widely used to transduce peptides/proteins into living cells [45]. We used this HIV-TAT sequence to modify the peptides (TAT-p + p-8 and TAT-SH3-3) for delivering them into ovarian cancer cells. The TAT-containing inhibitory short peptides were produced through commercial sources. An unrelated TAT-peptide was used as control. HIV-TAT modified inhibitory or control peptides $(10 \mu \mathrm{M})$ were added into the cell culture of SK-OV3 and incubated for various time periods. A FITC (fluorescein isothiocyanate)-conjugated HIV-TAT peptide was also synthesized and used to test the delivery efficiency for the proposed experiments beforehand. Since the accuracy of the experiments might be affected by cell proliferation, MTT (3-(4,5-dimethyl-2-thiazolyl)-2,5-diphenyl-2$\mathrm{H}$-tetrazolium bromide) assay were also performed. By comparing the growth/proliferation index with control peptide-treated cells, we confirmed that disrupting the SOS1/EPS8/ABI1 tri-complex had no significant effect on cell proliferation (data not shown). GST-pulldown assay was then performed to test the effects of TATcontaining inhibitory short peptides on ABI1-SOS1 and ABI1-EPS8 interactions. The results showed that peptide TAT-p $+p-8$, which was capable of disrupting ABI1EPS8 interaction in vitro, also efficiently blocked the binding of ABI1-EPS8 in vivo. The maximum effect was achieved at $24 \mathrm{~h}$ after administration of this peptide (Fig. 4c). In contrast, the peptide TAT-SH3-3 showed moderate inhibitory effect on the interaction between ABI1 and SOS1 in vivo. This might be due to the longer length and weaker penetration capability of the peptide (Fig. 4d).

\section{Evaluation of the efficacy of SOS1/EPS8/ABI1 targeting inhibitory short peptides in suppressing ovarian cancer metastasis}

Since the integrity of SOS1/EPS8/ABI1 is essential for LPA-induced ovarian cancer metastasis [4], these inhibitory short peptides are expected to inhibit the invasion of cancer cells. Two metastatic cell lines SK-OV3 and HEY were used in the study. The cells were treated with the TAT-fused peptides (TAT-p + p-8 and TAT-SH3-3) for $24 \mathrm{~h}$ before LPA-stimulation. Matrigel invasion assay was performed to test the suppressive capabilities of these inhibitory short peptides on cell invasion. It was found that the peptide TAT-p + p-8 could significantly block LPA-induced invasion in both SK-OV3 and HEY cells. These results suggested that the peptide TAT-p + p-8, which was capable of disrupting SOS1/EPS8/ABI1 tri-complex, could effectively suppress the invasion of ovarian cancer cells. The other peptide TAT-SH3-3, also showed some inhibitory effects on cell invasion, but the inhibition was not statistically significant (Fig. 5a).

We have previously used a well-established peritoneal seeding model to study ovarian cancer metastasis $[13,14]$. We used this model again to test the efficacy of the inhibitory peptides in suppressing metastatic colonization of ovarian cancer cells. Briefly, metastatic ovarian cancer cell lines SK-OV3 or HEY were intraperitoneally injected into $\mathrm{nu} / \mathrm{nu}$ mice. Seventy-two hours after injection, mice were intraperitoneally injected with PBS, TAT-fused scramble peptides or TAT-fused inhibitory short peptides, once every 2 days for 4 weeks. The mice were then sacrificed to collect the metastatic implants. By comparing the weight of the metastatic implants from animals receiving inhibitory short peptides to those receiving PBS or scrambled control peptides, we found that TAT-p $+\mathrm{p}-8$, a TATfused inhibitory peptide, could significantly suppress the metastasis of ovarian cancer cells (Fig. 5b, c). The inhibitory effects of peptide TAT-SH3-3 on metastatic colonization was not as statistically significant as TAT$\mathrm{p}+\mathrm{p}-8$. These results were in accordance with our findings of the invasion assay.

\section{Discussion}

One of the most characteristic metastasis-promoting functions of LPA is its ability to stimulate cell migration [46]. Our previous studies have elucidated the signaling events associated with LPA-stimulated ovarian cancer 


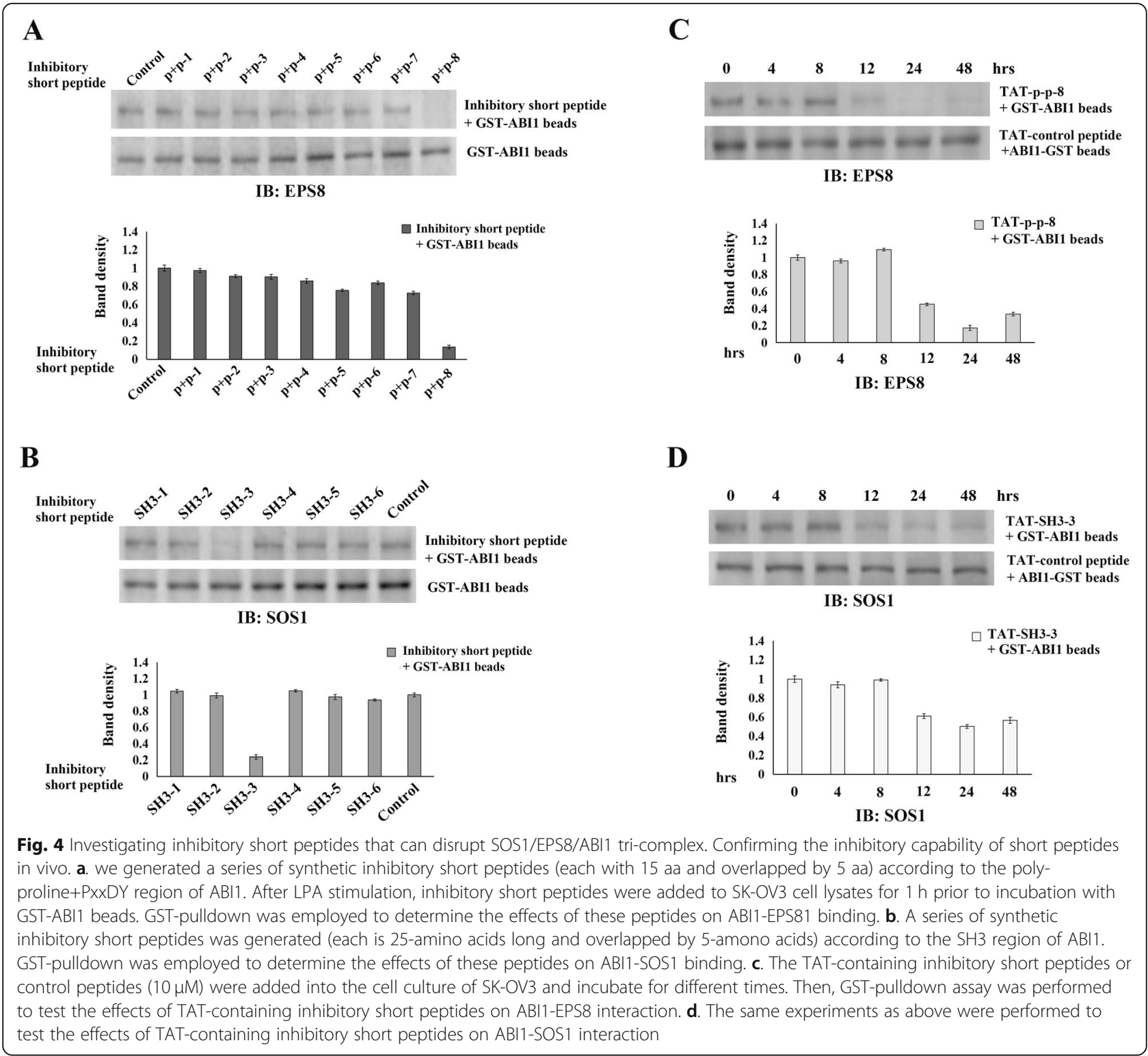

metastasis $[13,14]$, and found that LPA induced cytoskeleton reorganization as well as cancer cell migration through Rac activation. We also identified SOS1/EPS8/ ABI1 tri-complex, a Rac-GEF, as a component essential for the elevated Rac activity [14]. With the aid of a wellestablished peritoneal seeding model [37], we demonstrated that the presence of SOS1/EPS8/ABI1 tri-complex correlated well to the metastatic potential of ovarian cancer cells, and an intact SOS1/EPS8/ABI1 tricomplex is required for Rac activation. Therefore, we thought that investigating the interaction models of these three proteins might be helpful in developing new anticancer drugs.

SOS1 protein $(150 \mathrm{kDa})$ is composed of several domains and functions as a dual GEF of Ras and Rac in different steps of signaling cascade. The C- terminal segment of SOS1 contains a proline-rich domain (PxxP), through which it interacts with the SH3 domains of ABI1. In its central segment, SOS1 has two domains, REM (Ras exchanger motif) and CDC25 (cell division cycle 25), that can catalyze the exchange of GDP-GTP in Ras. The N-terminal segment contains a Dbl homology (DH) domain in tandem with a pleckstrin homology $(\mathrm{PH})$ domain, which stimulates GTP/GDP exchange for Rac. SOS1 displays Ras specificity, when associated with Grb2. On the contrary, SOS1 acts as a Rac-GEF, when engaged in a complex with EPS8 and ABI1 [43]. Grb2 and ABI1 bind to the same site on SOS1 through their respective $\mathrm{SH} 3$ domains, thus determining the formation of either a SOS1/Grb2 or a SOS1/ABI1/Eps8 complex, endowed with Ras or Rac-specific GEF 


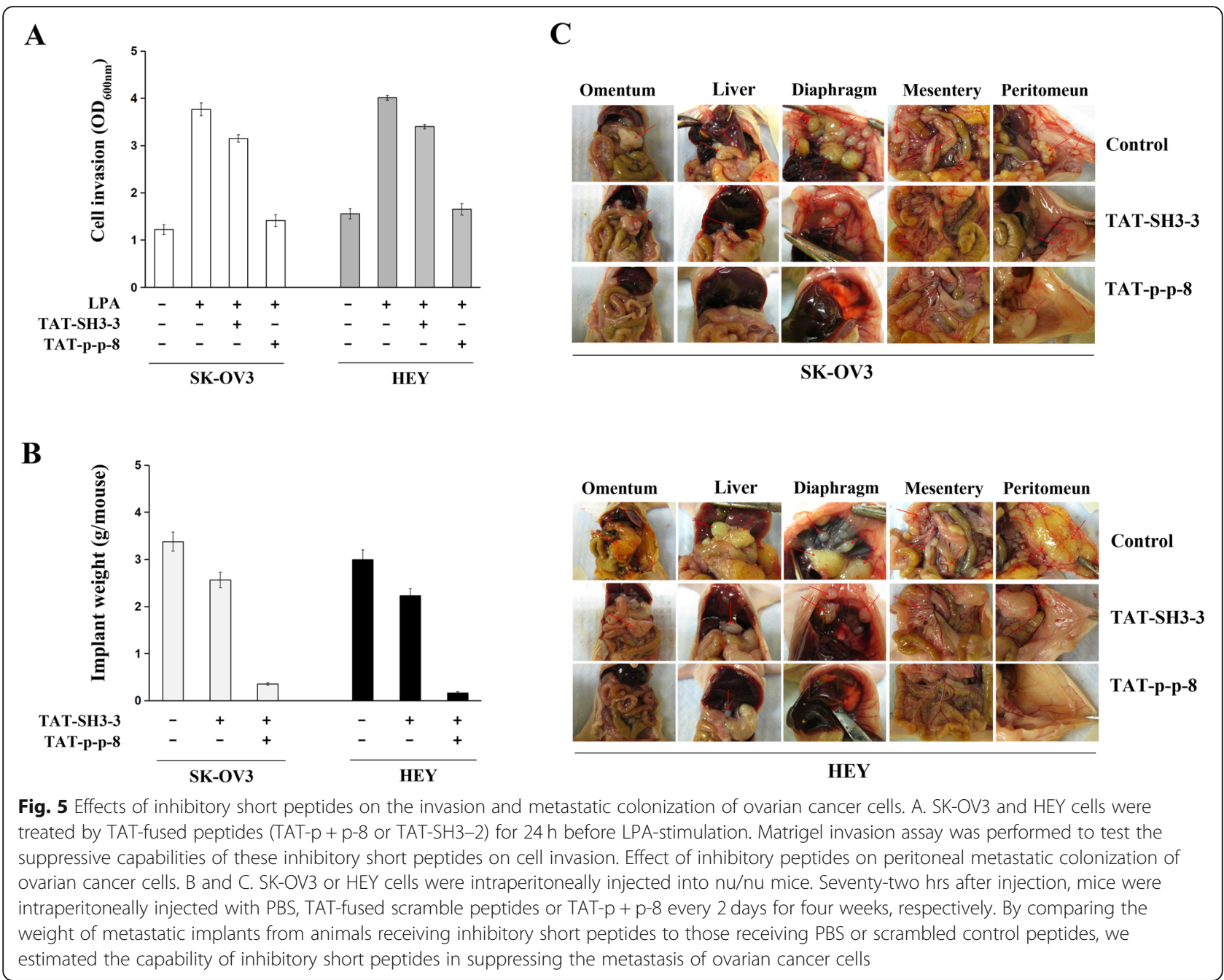

activities, respectively [17]. EPS8, a substrate of the EGFR kinase, contains three major domains: a N-terminal phosphotyrosine binding (PTB) domain, a central SH3 domain, and a C-terminal "effector region" domain [21]. The SH3 domain of EPS8 tends to combine with the PxxDY motif, which happen to be present in ABI1, rather than the classic proline rich motif PxxP [23]. The C-terminal "effector region" of EPS8 can facilitate the Rac-activating complex SOS1/ EPS8/ABI1 to its proper subcellular site (actin filaments), and affect the substrate specificity of SOS1 [22]. ABI1 was reported to be a general coordinator of kinase-substrate interactions. It is involved in the formation of many macromolecule complexes related to cytoskeleton regulation, such as Abl/ABI1/ WAVE2 [39], Napl/PIRl21/ABI1/WAVE [40], and cAbl/ABI1/Mena [41]. The N-terminal of ABI1 consists of WAB (wave binding domain), SNARE, and HHR domains. Moreover, there is a non-classic proline rich motif PxxDY located in the C-terminal of
ABI1, which can specifically bind to the $\mathrm{SH} 3$ domain of EPS8 [26]. The C-terminal of ABI also has a polyproline structure and a $\mathrm{SH} 3$ site, which can bind to carboxy-terminal portion of Abl [47].

Although Scita et al. had suggested that the SOS1/ ABI1/EPS8 complex mediated the signal transduction from Ras to Rac in 1999 [20], the involved molecular mechanism is not well understood. They thought that ABI1 bond to the proline rich domain of SOS1 through its SH3 domain and to the SH3 domain of EPS8 through its proline domain. They also suggested that ABI1 might serve as a scaffold protein connecting SOS1 and EPS8 [22]. This model was verified by Innocenti et al. later $[17,18]$, but various questions remained to be answered. First, the existence of the tri-complex under physiological conditions should be verified. In this study, we performed Co-IP in metastatic ovarian cancer cell line SK-OV3 after LPA stimulation. The results showed that both SOS1 and EPS8 were detected in the anti-ABI1 immunoprecipitates. Then, we further demonstrated that 
there were interactions between ABI1-SOS1 and ABI1EPS8, but SOS1 and EPS8 could not directly bind with each other. These results proved the existence of an endogenous SOS1/EPS8/ABI1 tri-complex, and the role of ABI1 as a scaffold protein holding together SOS1 and EPS8. To further investigate the binding sites in ABI1 for SOS1 and EPS8, we divided ABI1 into different regions, and used Co-IP assay to detect the regions responsible for protein interactions. Our results indicated that the SH3 region of ABI1 mediated ABI1-SOS1 binding, as described by the previous studies. We also found that the poly-proline+PxxDY region of ABI1 was responsible for its interaction with EPS8, which had not been reported yet. Besides that, we also demonstrated that the proline-rich region of SOS1 and the SH3 region of EPS8 mediated their interactions with ABI1, respectively.

In the recent years, inhibitory peptides have been successfully used to specifically disrupt signaling complexes, thereby blocking relevant biological events, which provides valuable insights into the development of peptidetype drugs [33, 34]. Various cargo sequences including the HIV-TAT sequence have been employed to assist the inhibitory peptides in penetrating the plasma membrane [45]. Since none of members in SOS1/EPS8/ABI1 tri-complex is dispensable in the Rac activation, and ABI1 acts as a scaffold protein, we hypothesize that ABI1 may be an ideal target to design anti-tumor drugs.

Based on the regions of ABI1 that were found responsible for SOS1 and EPS8 bindings, we generated a series of synthetic inhibitory short peptides. Efficient inhibitory short peptides were supposed to disrupt the protein-protein interactions. Through GST-pulldown assay and Co-IP, the short peptide $\mathrm{p}+\mathrm{p}-8$ (ppppppppvdyedee) was identified as the one capable of blocking ABI1-EPS8 interaction, while SH3-3 (ekvvaiydytkdkddelsfmegaii) as the one could effectively inhibit the combination of ABI1 and SOS1 in vitro.

Subsequently, we used a HIV-TAT sequence (YGKKRRQRRPP), an effective cell membrane penetrating peptide, to modify the screened inhibitory short peptides, so as to transfer the peptides into ovarian cancer cells. The results showed that the peptide TAT-p + p-8, which was capable of disrupting ABI1-EPS8 interaction in vitro, could also efficiently block the binding of ABI1EPS8 in vivo. However, the peptide TAT-SH3-3 was not efficiently enough to block the interaction between ABI1 and SOS1 in vivo. The longer length and weaker penetration capability of the peptide might be the reason for the worse inhibitory efficiency of the peptide.

Since the purpose of our study was to eventually block the downstream signaling pathways and biological events mediated by the SOS1/EPS8/ABI1 tricomplex through disrupting proteins interactions, we evaluated the efficacy of the selected inhibitory short peptides in suppressing ovarian cancer metastasis. Using Matrigel invasion assay as well as peritoneal metastatic colonization model, we found that the inhibitory short peptide TAT-p + p- 8 could effectively suppress the invasion and metastasis of ovarian cancer cells. However, the inhibitory effects of peptide TATSH3-3 on cell invasion and metastatic colonization was not as statistically significant as TAT-p $+\mathrm{p}-8$. Since peptide can be degradation by enzymes, and the stability of peptides mainly depends on primary and secondary structure. Thus, peptide SH-3 may be more easily degraded by enzymes, resulting in poor inhibitory potential in vivo. In the following studies, we will adopt chemical strategies, such as $\mathrm{N}$ and $\mathrm{C}$ termini modifications, to modify the peptides to increase their in vivo stabilities. Then the stability and pharmacokinetic profile of the peptide will be evaluated.

\section{Conclusions}

The specific involvement of EPS8/ABI1/SOS1 tri-complex in ovarian cancer metastasis suggests that this tricomplex-targeted drugs may have less effects on noncancer tissues than on cancer tissues. As an antagonist of the parental protein for the same binding site, short peptides have high specificity and affinity to the targeting proteins. This is the basis on which short peptides are expected to serve as a starting point for pharmacochemistry. However, short peptides may still have potential toxicity to normal tissues, which needs to be further evaluated in future studies. The fact that ovarian cancer is mainly confined to the peritoneal cavity $[5,6]$ ensures the feasibility of locally delivering therapeutic peptides at effective dosages. This study may provide a theoretical basis for the future development of anticancer drugs.

\section{Abbreviations cancer \\ Acknowledgments \\ Not Applicable. \\ Consent to publication Not Applicable.}

DMEM: Dulbecco's modified Eagle's medium; FBS: Fetal bovine serum; FBSL: Fetal bovine serum; GEF: Guanosine monophosphate exchange factor; IPTG: Isopropy- $\beta$-D-thiogalactoside; LPA: Lysophosphatic acid; OC: Ovarian

\section{Authors' contributions}

$\mathrm{HC}$ has made substantial contributions to concepts and design, as well as data acquisition, analysis and interpretation. $\mathrm{XY}$ and $\mathrm{CL}$ participated in drafting the manuscript, and revising it based on reviewers' comments. $Y Z$ and $W Z$ agreed to be responsible for all aspects of the work to ensure that issues related to the accuracy or integrity of any part of the work were properly investigated and resolved, and that the version to be published was finally approved. All authors have read and approved the manuscript.

\section{Authors' information}

1. Huijun Chen, the Corresponding Author, MD and phD, deputy chief physician, E-mail: karrel@sina.com

2. Xuechen Yu, MD, attending doctor, E-mail: yuxz6406@126.com 
3. Chuan Liang, MD and phD, attending doctor, E-mail: 810934752@qq.com 4. Yuanzhen Zhang, MD, professor, E-mail: zhangyuanzhen@vip.sina.com 5.Wei Zhang, MD, professor, E-mail: zw6676@163.com Chuan Liang works at Department of Cardiothoracic vascular surgery, Zhongnan Hospital of Wuhan University, Wuhan 430071, Hubei, China. All other authors work at Department of Gynaecology and Obstetrics, Zhongnan Hospital of Wuhan University, Wuhan 430071, Hubei, China.

\section{Funding}

This study was supported by National Natural Science Funds of China (Grant No. 81202071). The funding bodies had no role in the design of the study, analysis of data and in the writing of the manuscript.

\section{Availability of data and materials}

The data supporting the conclusions of this article is included within the article and supplementary material.

\section{Ethics approval and consent to participate}

All animal experiment procedures were approved by the Medical Ethics Committee of Zhongnan Hospital of Wuhan University and met the requirement of Animal Biosafety Level-3 Laboratory of Wuhan University.

\section{Competing interests}

The authors declare that there are no conflicts of interest in this manuscript.

\section{Author details}

${ }^{1}$ Department of Gynaecology and Obstetrics, Zhongnan Hospital of Wuhan University, Wuhan 430071, Hubei, China. ${ }^{2}$ Department of Cardiothoracic vascular surgery, Zhongnan Hospital of Wuhan University, Wuhan 430071, Hubei, China.

\section{Received: 16 January 2019 Accepted: 23 August 2019}

\section{Published online: 05 September 2019}

\section{References}

1. Siegel R, Ma J, Zou Z, Jemal A. Cancer statistics, 2014. CA Cancer J Clin. 2014;64(1):9-29. https://doi.org/10.3322/caac.21208.

2. Ray-Coquard I, Morice P, Lorusso D, Prat J, Oaknin A, Pautier P, et al. ESMO Guidelines Committee. Non-epithelial ovarian cancer: ESMO Clinical Practice Guidelines for diagnosis, treatment and follow-up. Ann Oncol. 2018; 29(Supplement_4):iv1-iv18. https://doi.org/10.1093/annonc/mdy001.

3. Argento M, Hoffman $P$, Gauchez AS. Ovarian cancer detection and treatment: current situation and future prospects. Anticancer Res. 2008; 28(5B):3135-8.

4. Vaughan S, Coward JI, Bast RC Jr, Berchuck A, Berek JS, Brenton JD, et al. Rethinking ovarian cancer: recommendations for improving outcomes. Nat Rev Cancer. 2011;11(10):719-25. https://doi.org/10.1038/nrc3144.

5. Landen CN Jr, Birrer MJ, Sood AK. Early events in the pathogenesis of epithelial ovarian cancer. J Clin Oncol. 2008;26(6):995-1005. https://doi.org/1 0.1200/JCO.2006.07.9970

6. Lengyel E. Ovarian cancer development and metastasis. Am J Pathol. 2010 177(3):1053-64. https://doi.org/10.2353/ajpath.2010.100105.

7. Jesionowska A, Cecerska-Heryc E, Matoszka N, Dolegowska B. Lysophosphatidic acid signaling in ovarian cancer. J Recept Signal Transduct Res. 2015;35(6):578-84. https://doi.org/10.3109/10799893.2015.1026444.

8. Pua TL, Wang FQ, Fishman DA. Roles of LPA in ovarian cancer development and progression. Future Oncol. 2009;5(10):1659-73. https:// doi.org/10.2217/fon.09.120

9. Fang X, Schummer M, Mao M, Yu S, Tabassam FH, Swaby R, et al. Lysophosphatidic acid is a bioactive mediator in ovarian cancer. Biochim Biophys Acta. 2002;1582(1-3):257-64.

10. Kim KS, Sengupta S, Berk M, Kwak YG, Escobar PF, Xu Y, et al. Hypoxia enhances lysophosphatidic acid responsiveness in ovarian cancer cells andlysophosphatidic acid induces ovarian tumor metastasis in vivo. Cancer Res. 2006;66(16):7983-90.

11. Yu S, Murph MM, Lu Y, Liu S, Hall HS, Liu J, et al. Lysophosphatidic acid receptors determine tumorigenicity and aggressiveness of ovarian cancer cells. J Natl Cancer Inst. 2008;100(22):1630-42. https://doi.org/1 0.1093/jnci/djn378.
12. Wang P, Wu X, Chen W, Liu J, Wang X. The lysophosphatidic acid (LPA) receptors their expression and significance in epithelial ovarian neoplasms. Gynecol Oncol. 2007;104(3):714-20.

13. Yu X, Zhang Y, Chen $\mathrm{H}$. LPA receptor 1 mediates LPA-induced ovarian cancer metastasis: an in vitro and in vivo study. BMC Cancer. 2016;16(1):846.

14. Chen H, Wu X, Pan ZK, Huang S. Integrity of SOS1/EPS8/ABI1 tri-complex determines ovarian cancer metastasis. Cancer Res. 2010;70(23):9979-90. https://doi.org/10.1158/0008-5472.

15. Pierre $S$, Bats AS, Coumoul X. Understanding SOS (son of Sevenless). Biochem Pharmacol. 2011;82(9):1049-56. https://doi.org/10.1016/j.bcp.2011.07.072.

16. Schmidt A, Hall A. Guanine nucleotide exchange factors for rho GTPases: turning on the switch. Genes Dev. 2002;16(13):1587-609.

17. Innocenti $M$, Tenca $P$, Frittoli $E$, Faretta $M$, Tocchetti $A$, Di Fiore PP, et al. Mechanisms through which Sos-1 coordinates the activation of Ras and Rac. J Cell Biol. 2002;156(1):125-36.

18. Innocenti M, Frittoli E, Ponzanelli I, Falck JR, Brachmann SM, Di Fiore PP, et al. Phosphoinositide 3-kinase activates Rac by entering in a complex with Eps8, Abi1, and Sos-1. J Cell Biol. 2003;160(1):17-23.

19. Mitra S, Lee JS, Cantrell M, Van den Berg CL. C-Jun N-terminal kinase 2 (JNK2) enhances cell migration through epidermal growth factor substrate 8 (EPS8). J Biol Chem. 2011;286(17):15287-97. https://doi.org/10.1074/jbc.M1 09.094441.

20. Scita G, Nordstrom J, Carbone R, Tenca P, Giardina G, Gutkind S, et al. EPS8 and E3B1 transduce signals from Ras to Rac. Nature. 1999;401(6750):290-3.

21. Di Fiore PP, Scita G. Eps8 in the midst of GTPases. Int J Biochem Cell Biol. 2002;34(10):1178-83.

22. Scita G, Tenca P, Areces LB, Tocchetti A, Frittoli E, Giardina G, et al. An effector region in Eps8 is responsible for the activation of the Rac-specific GEF activity of Sos-1 and for the proper localization of the Rac-based actinpolymerizing machine. J Cell Biol. 2001;154(5):1031-44.

23. Li YH, Xue TY, He YZ, Du JW. Novel oncoprotein EPS8: a new target for anticancer therapy. Future Oncol. 2013;9(10):1587-94. https://doi.org/10.221 7/fon.13.104.

24. Kotula L. Abi1, a critical molecule coordinating actin cytoskeleton reorganization with PI-3 kinase and growth signaling. FEBS Lett. 2012; 586(17):2790-4. https://doi.org/10.1016/j.febslet.2012.05.015.

25. Fan PD, Goff SP. Abl interactor 1 binds to sos and inhibits epidermal growth factor- and v-Abl-induced activation of extracellular signal-regulated kinases. Mol Cell Biol. 2000;20(20):7591-601.

26. Mongioví AM, Romano PR, Panni S, Mendoza M, Wong WT, Musacchio A, et al. A novel peptide-SH3 interaction. EMBO J. 1999;18(19):5300-9.

27. Ahram M, Mustafa E, Zaza R, Abu Hammad S, Alhudhud M, Bawadi R, et al. Differential expression and androgen regulation of microRNAs and metalloprotease 13 in breast cancer cells. Cell Biol Int. 2017;41(12):1345-55. https://doi.org/10.1002/cbin.10841.

28. Benzon B, Glavaris SA, Simons BW, Hughes RM, Ghabili K, Mullane P. Combining immune check-point blockade and cryoablation in an immunocompetent hormone sensitive murine model of prostate cancer. Prostate Cancer Prostatic Dis. 2018;21(1):126-36. https://doi.org/10.1038/ s41391-018-0035-z.

29. Stone TA, Deber CM. Therapeutic design of peptide modulators of proteinprotein interactions in membranes. Biochim Biophys Acta Biomembr. 2017; 1859(4):577-85. https://doi.org/10.1016/j.bbamem.2016.08.013.

30. Meireles LM, Mustata G. Discovery of modulators of protein-protein interactions: current approaches and limitations. Curr Top Med Chem. 2011 ; 11(3):248-57.

31. Cunningham AD, Qvit N, Mochly-Rosen D. Peptides and peptidomimetics as regulators of protein-protein interactions. Curr Opin Struct Biol. 2017:44:5966. https://doi.org/10.1016/j.sbi.2016.12.009.

32. Helmer D, Schmitz K. Peptides and peptide analogs to inhibit proteinprotein interactions. Adv Exp Med Biol. 2016;917:147-83. https://doi.org/10.1 007/978-3-319-32805-8_8.

33. Fosgerau K, Hoffmann T. Peptide therapeutics: current status and future directions. Drug Discov Today. 2015;20(1):122-8. https://doi.org/10.1016/j. drudis.2014.10.003.

34. Ilert-Miklaszewska A, Poleszak K, Kaminska B. Short peptides interfering with signaling pathways as new therapeutic tools for cancer treatment. Future Med Chem. 2017;9(2):199-221. https://doi.org/10.4155/fmc-2016-0189.

35. Bae DG, Kim TD, Li G, Yoon WH, Chae CB. Anti-flt1 peptide, a vascular endothelial growth factor receptor 1-specific hexapeptide, inhibits tumor growth and metastasis. Clin Cancer Res. 2005;11(7):2651-61. 
36. Huang S, New L, Pan Z, Han J, Nemerow GR. Urokinase plasminogen activator/urokinase-specific surface receptor expression and matrix invasion by breast cancer cells requires constitutive p38alpha mitogen-activated protein kinase activity. J Biol Chem. 2000;275(16):12266-72.

37. Shaw TJ, Senterman MK, Dawson K, Crane CA, Vanderhyden BC Characterization of intraperitoneal, orthotopic, and metastatic xenograft models of human ovarian cancer. Mol Ther. 2004;10(6):1032-42.

38. Stradal T, Courtney KD, Rottner K, Hahne P, Small JV, Pendergast AM. The Abl interactor proteins localize to sites of actin polymerization at the tips of lamellipodia and filopodia. Curr Biol. 2001;11(11):891-5.

39. Leng Y, Zhang J, Badour K, Arpaia E, Freeman S, Cheung P, et al. Abelsoninteractor-1 promotes WAVE2 membrane translocation and Abelsonmediated tyrosine phosphorylation required for WAVE2 activation. Proc Nat Acad Sci U S A. 2005;102(4):1098-103.

40. Innocenti M, Zucconi A, Disanza A, Frittoli E, Areces LB, Steffen A, et al. Abi1 is essential for the formation and activation of a WAVE2 signalling complex. Nat Cell Biol. 2004;6(4):319-27.

41. Tani K, Sato S, Sukezane T, Kojima H, Hirose H, Hanafusa H, et al. Abl interactor 1 promotes tyrosine 296 phosphorylation of mammalian enabled (Mena) by c-Abl kinase. J Biol Chem. 2003 Jun 13; 278(24):21685-92. Mol Cell Biol. 2004;24(11):4979-93.

42. Echarri A, Lai MJ, Robinson MR, Pendergast AM. Abl interactor 1 (Abi-1) wave-binding and SNARE domains regulate its nucleocytoplasmic shuttling, lamellipodium localization, and wave-1 levels. Mol Cell Biol. 2004;24(11): 4979-93.

43. Nimnual A, Bar-Sagi D. The two hats of SOS. Sci STKE. 2002;2002(145):pe36.

44. Sekino S, Kashiwagi Y, Kanazawa H, Takada K, Baba T, Sato S, et al. The NESH/Abi-3-based WAVE2 complex is functionally distinct from the Abi-1based WAVE2 complex. Cell Commun Signal. 2015;13:41. https://doi.org/1 0.1186/s12964-015-0119-5.

45. Joliot A, Prochiantz A. Transduction peptides: from technology to physiology [J]. Nat Cell Biol. 2004;6(3):189-96.

46. Willier S, Butt E, Grunewald TG. Lysophosphatidic acid (LPA) signalling in cell migration and cancer invasion: a focussed review and analysis of LPA receptor gene expression on the basis of more than 1700 cancer microarrays. Biol Cell. 2013;105(8):317-33. https://doi.org/10.1111/boc.2 01300011

47. Shi Y, Alin K, Goff SP. Abl-interactor-1, a novel SH3 protein binding to the carboxy-terminal portion of the Abl protein, suppresses $\mathrm{v}$-abl transforming activity. Genes Dev. 1995 Nov 1;9(21):2583-97.

\section{Publisher's Note}

Springer Nature remains neutral with regard to jurisdictional claims in published maps and institutional affiliations.

Ready to submit your research? Choose BMC and benefit from:

- fast, convenient online submission

- thorough peer review by experienced researchers in your field

- rapid publication on acceptance

- support for research data, including large and complex data types

- gold Open Access which fosters wider collaboration and increased citations

- maximum visibility for your research: over $100 \mathrm{M}$ website views per year

At $\mathrm{BMC}$, research is always in progress.

Learn more biomedcentral.com/submissions 